\section{Dentin sialoprotein, dentin phosphoprotein, enamelysin and ameloblastin: tooth- specific molecules that are distinctively expressed during murine dental differentiation}

\section{Bègue-Kirn C, Krebsbach PH, Bartlett JD, Butler WT: Dentin sialoprotein,} dentin phosphoprotein, enamelysin and ameloblastin: tooth-specific molecules that are distinctively expressed during murine dental differentiation. Eur J Oral Sci 1998; 106: 963-970. (C) Eur J Oral Sci, 1998

Dentin sialophosphoprotein [designated DSPP and cleaved into dentin sialoprotein (DSP) and dentin phosphoprotein (DPP)], enamelysin and ameloblastin are each expressed in unique fashions during tooth development. It is possible that these components participate in cell differentiation and the conversion of unmineralized matrix into mineralized structures. In order to delineate the timing and the positioning of these three molecules in a physiological context, we compared their expression profiles by performing in situ hybridization experiments on consecutive sections in developing mouse tissues. Hybridization signals were uniquely detected for DSPP mRNA in odontoblasts and preameloblasts, for enamelysin mRNA in odontoblasts and in the facing ameloblast layer, and for ameloblastin mRNA in preodontoblasts, polarizing odontoblasts and ameloblasts. Immunohistochemistry showed that DSP and ameloblastin transcripts were translated into proteins that were deposited at the apical pole of the differentiated cells (odontoblasts and ameloblasts, respectively). The interrelated expression profiles found for these tooth-specific molecules illustrate the importance of a specific molecular network to initiate highly regulated processes such as cytodifferentiation and the subsequent mineralization.

\section{Catherine Bègue-Kirn', Paul H. Krebsbach ${ }^{2}$, John D. Bartlett ${ }^{3}$, William T. Butler ${ }^{1}$}

${ }^{1}$ Department of Basic Sciences, Dental Branch, University of Texas Houston Health Science Center, Houston, TX, ²Department of Oral Medicine, Pathology and Surgery, School of Dentistry, University of Michigan, Ann Arbor, MI, ${ }^{3}$ Department of Biomineralization, Forsyth Dental Center, Boston, MA, USA

\begin{abstract}
Corresponding author: William T. Butler, Ph.D., Dental Branch, Room 3.108C, University of Texas Houston Health Science Center, 6516 John Freeman Avenue, Houston, TX 77030, USA

Telefax: +1-713-5004568

E-mail: wbutler@mail.db.uth.tmc.edu

Key words: dentin sialoprotein; dentin phosphoprotein; enamelysin; ameloblastin; tooth mineralization
\end{abstract}

Accepted for publication June 1998
Odontogenesis and dental cytodifferentiations are highly regulated events that result from sequential and reciprocal epithelio-mesenchymal interactions $(1,2)$. The transmission of information between these two adjacent tissues during differentiation requires either heterotypic direct contacts or matrixmediated cell interactions (3-5). A stage-specific inner dental epithelium promotes the terminal differentiation of preodontoblasts into post-mitotic, cytologically differentiated odontoblasts (polarized odontoblasts) that progressively become fully differentiated odontoblasts and secrete the compon- ents of predentin and dentin at their apical pole (1). The presence of this newly synthesized matrix at the epithelio-mesenchymal interface is associated with events that trigger the withdrawal of preameloblasts from the cell cycle and subsequent terminal differentiation of ameloblasts (1). Ameloblasts progress through three main developmental stages: 1) presecretory; 2) secretory; and 3) maturation stages (6). In a positional sense, the polarization of ameloblasts is correlated with the first appearance of predentin, while the secretion of enamel matrix components by ameloblasts is correlated with the 
presence of predentin components and their progressive conversion into dentin. In both situations (dentinogenesis and amelogenesis), the expression of specific gene products is required prior to the onset of mineral formation. The presence at the epithelio-mesenchymal junction of a specific network of secreted molecules is believed to participate directly or indirectly in the biomineralization processes.

In forming predentin and dentin, odontoblasts secrete a unique set of extracellular matrix (ECM) macromolecules comprised essentially of type I collagen (7) and non-collagenous macromolecules. Dentin ECM includes molecules that are also found in bone, such as the proteoglycans decorin and biglycan (8), osteonectin (ON) (9), osteopontin (OPN) (10), osteocalcin (OCN) (11), bone sialoprotein (BSP) (12), and dentin matrix protein 1 (Dmp1) (13). At least two distinct proteins isolated from dentin ECM are found only in tooth structures (14): dentin sialoprotein (DSP) (15) and dentin phosphoprotein (DPP, also called phosphophoryn) $(15,16)$. DSP is a $53 \mathrm{kDa}$ sialic acid-rich glycoprotein of unknown function $(17,18)$. DPP is a highly phosphorylated protein rich in phosphoserine and aspartic acid. Considerable evidence shows that DPP is involved in initiating early apatite crystal formation at the predentin-dentin border (19-21). It may also contribute to the regulation of crystal growth as mineralization in forming dentin proceeds $(20,22)$. Immunolocalization and in situ hybridization experiments revealed that DSP is not only expressed by differentiating and mature odontoblasts, but also by a specific population of ameloblast precursors present in the inner dental epithelium (23-26). Recent studies showed the existence of one transcript (designated DSPP $^{1}$ for dentin sialophosphoprotein) that included DSP and DPP sequences in the $5^{\prime}$ and $3^{\prime}$ regions respectively $(27,28)$. In addition, the strict in vivo and in vitro coexpression of DSP and DPP has been demonstrated at the transcriptional level, using riboprobes specific for sequences coding for each protein, as well as for the intervening region present between DSP and DPP coding regions (24). Taken together, the different studies indicate that DSP and DPP are transcribed as a single transcript coding for a single precursor protein that is cleaved into two smaller proteins.

Other tooth-specific ECM molecules are currently known to be expressed during ameloblast differentiation and subsequent amelogenesis. Enamel matrix is composed of two classes of pro-

\footnotetext{
${ }^{1}$ Throughout the text, the abbreviation DSPP designates the mRNA which encodes the combined DSP and DPP transcript. The terms DSP and DPP are used to designate individual proteins isolated from dentin ECM.
}

teins: the amelogenins and the non-amelogenin proteins such as enamelins and ameloblastin (29-32). Ameloblastin mRNA encodes an open reading frame of 422 amino acids, predicted as a $43.5 \mathrm{kDa}$ secreted (pre-peptide removed) acidic protein $(\mathrm{pI}=5.54)$ rich in proline, glycine and leucine (31). A smaller mRNA variant, amelin, derived from the same gene as ameloblastin was simultaneously identified by CERNÝ et al. (33). The resulting proteins (ameloblastin and amelin) are structurally related, and only 15 amino acids present in the $\mathrm{NH}_{2}$-terminal portion of ameloblastin are deleted from the amelin sequence $(31,34)$. Using an ameloblastin antibody raised against the COOH-terminal portion, LEE et al. (35) showed that ameloblastin exhibited a specific expression in the cytoplasm of differentiating and secretory ameloblasts that, unlike amelogenin, remained highly expressed as ameloblasts mature. An antibody raised against the entire recombinant amelin reacted strongly with newly secreted enamel and to a weaker extent with other structures also recognized by the ameloblastin antibody (34).

In addition to ECM molecules, the presence of the following in tooth matrix have been reported: 1) growth factors $(36,37) ; 2)$ serum-derived proteins (38); 3) lipids (39); and 4) degradative enzymes such as proteinases (40-44). Among these latter constituents, enamelysin is a secreted matrix metalloproteinase that is 376 amino acids in length (pre- and pro- peptides removed), has a predicted molecular mass of $42.5 \mathrm{kDa}$, and does not belong to the collagenase or the stromelysin families (43). Northern analysis revealed that enamelysin mRNA is expressed at the early transition and late maturation stages of developing enamel organs, as well as in pulps, and thus displays a unique tooth-specific, developmentally-regulated expression pattern (45).

In the present study, we show a precise comparative analysis of the temporal and spatial distribution of three transcripts specifically expressed during tooth development: DSPP, enamelysin and ameloblastin. These three gene expression patterns were also correlated with the histochemical appearance of mineral at the predentin-enamel organ interface. Furthermore, in order to verify the presence of the corresponding translation products at the epitheliomesenchymal junction, experiments utilizing immunohistochemistry and in situ hybridization for DSP and ameloblastin were conducted on adjacent tissue sections.

\section{Material and methods Tissues}

Serial sections $(5-7 \mu \mathrm{m})$ of newborn and 4-d-old Swiss mouse heads were prepared in a sagittal 
plane, attached on "superfrost Plus" microscope slides (Fisher Scientific, Pittsburgh, PA, USA) and used for either in situ hybridization or immunohistochemistry. Some sections were stained with the Von Kossa technique (46) in order to correlate specific labeling with the mineral content of the ECM.

\section{In situ hybridization}

Antisense and sense RNA probes were labeled with digoxigenin-dUTP using the appropriate SP6, T3 or $\mathrm{T} 7$ in vitro transcription system (Boehringer Mannheim, Indianapolis, IN, USA). The murine DSPP and ameloblastin probes have been previously described $(24,35)$. The murine enamelysin cDNA fragment was recently amplified by RT-PCR using total RNA from mouse tooth germs and degenerate oligonucleotide primers which amplified a cDNA fragment encoding the catalytic domain (43). Cryosections were fixed and pretreated as described (47). The RNA probes were diluted at $10 \mathrm{ng} / \mathrm{ml}$ of hybridization solution ( $10 \mathrm{mM}$ Tris$\mathrm{HCl}, \mathrm{pH} 8.0,50 \%$ formamide, $10 \%$ dextran sulfate, 12.5X Denhardt's solution, 2X SSC, 0.5\% SDS, $250 \mu \mathrm{g} / \mathrm{ml}$ salmon sperm DNA, $5 \mathrm{mg} / \mathrm{ml}$ sodium pyrophosphate) and hybridized overnight at $50^{\circ} \mathrm{C}$. Sections were washed as follows: 1) $2 \mathrm{X} \mathrm{SSC,} 50 \%$ formamide at $60^{\circ} \mathrm{C}$ for $90 \mathrm{~min}$; 2) $\mathrm{H}_{2} \mathrm{O}$ for $2 \mathrm{~min}$; 3) RNase $T_{1} 2 \mathrm{U} / \mathrm{ml}$ (Boehringer Mannheim), RNase A 20-40 $\mu \mathrm{g} / \mathrm{ml}$ (Sigma, St. Louis, MO, USA) at $37^{\circ} \mathrm{C}$ for $30 \mathrm{~min}$; 4) $\mathrm{H}_{2} \mathrm{O}$ for $2 \mathrm{~min}$; and 5) $2 \mathrm{X} \mathrm{SSC}, 50 \%$ formamide at $60^{\circ} \mathrm{C}$ for $90 \mathrm{~min}$. Detection of a specific signal was carried out using a polyclonal anti-digoxigenin antibody conjugated to alkaline phosphatase, according to the manufacturer's instructions (Boehringer Mannheim). The sections were stained with safranin-O (Fisher Scientific) and examined using bright-field optics.

\section{Immunohistochemistry}

Pretreatments. Cryosections stored at $-80^{\circ} \mathrm{C}$ were fixed in acetone and washed twice for $10 \mathrm{~min}$ each in PBS. Tissues were treated with $0.6 \%$ hydrogen peroxide in methanol for $30 \mathrm{~min}$ at room temperature to block endogenous peroxidase activity. In order to optimize the accessibility of epitopes, the rinsed sections (PBS, $10 \mathrm{~min}, 2$ times) were incubated in $1 \mathrm{mg} / \mathrm{ml}$ hyaluronidase (type-I from bovine testis; Sigma) in PBS for $30 \mathrm{~min}$ at $37^{\circ} \mathrm{C}$. The sections were rinsed (PBS, $10 \mathrm{~min}, 2$ times) and non-specific binding was inhibited by incubation in a PBS-blocking buffer, containing 3\% bovine serum albumin (bovine fraction V; Sigma), and $0.15 \%$ Tween 20 for $2-4 \mathrm{~h}$ at $37^{\circ} \mathrm{C}$.
Primary antibodies. Polyclonal antibodies to rat DSP were raised in rabbits (17). Anti-DSP antisera were passed successively through two columns consisting of Sepharose-bound 1) high molecular weight bone proteins; and 2) $\alpha_{2} \mathrm{HS}$-glycoprotein. The unbound fraction emerging from these columns was used for immunolocalization of DSP.

Rabbit polyclonal antibodies raised against amino-acid residues 175 to 348 of rat ameloblastin were produced using standard procedures (35). Isolation of purified anti-ameloblastin $\mathrm{IgG}$ by affinity purification was achieved by using a recombinant ameloblastin affinity column.

$A B C$-peroxidase method. After pretreatments (see above), tissue sections were incubated for $1 \mathrm{~h}$ at $37^{\circ} \mathrm{C}$ in the presence of the primary antibody diluted in blocking buffer; for negative controls, we utilized blocking buffer alone or $10 \%$ normal goat serum. Sections were rinsed in blocking buffer (20-30 min, 2 times) and incubated for $30 \mathrm{~min}$ at $37^{\circ} \mathrm{C}$ in the presence of biotinylated, affinitypurified anti-rabbit IgG (Pierce, Rockford, IL, USA) diluted in blocking buffer. After two washes in blocking buffer of $20 \mathrm{~min}$ each, the sections were allowed to react with the freshly prepared biotinylated avidin-peroxidase complex (Immunopure ABC peroxidase; Pierce). After two washes in PBS of $10 \mathrm{~min}$ each, the presence of peroxidase was revealed by development for $2-5 \mathrm{~min}$ in $1 \mathrm{mg} / \mathrm{ml}$ 3,3'-diaminobenzidine (DAB Chromogen tablets; Dako, Carpinteria, CA, USA), diluted in PBS and containing $0.025 \%$ hydrogen peroxide.

\section{Results}

DSPP, enamelysin and ameloblastin mRNA detection in developing teeth

Using adjacent sections, the expression pattern of DSPP transcripts was compared to that of two other tooth-specific molecules, enamelysin and ameloblastin (Fig. 1).

DSPP transcripts were detected in polarizing odontoblasts and in functional odontoblasts depositing the extracellular matrix components of predentin-dentin (Fig. 1A). In addition, a distinct but weaker signal for DSPP mRNA was detected in presecretory ameloblasts (facing both polarizing and functional odontoblasts) but not in further differentiated ameloblasts (Fig. 1A). These observations are consistent with previous data (23-26).

In contrast, enamelysin transcripts were detected in both functional odontoblasts (but not polarizing odontoblasts) and the facing ameloblast layer (Fig. 1B). Enamelysin mRNA expression was first detected in these two tissues coincident with the initiation of predentin formation (see arrow 

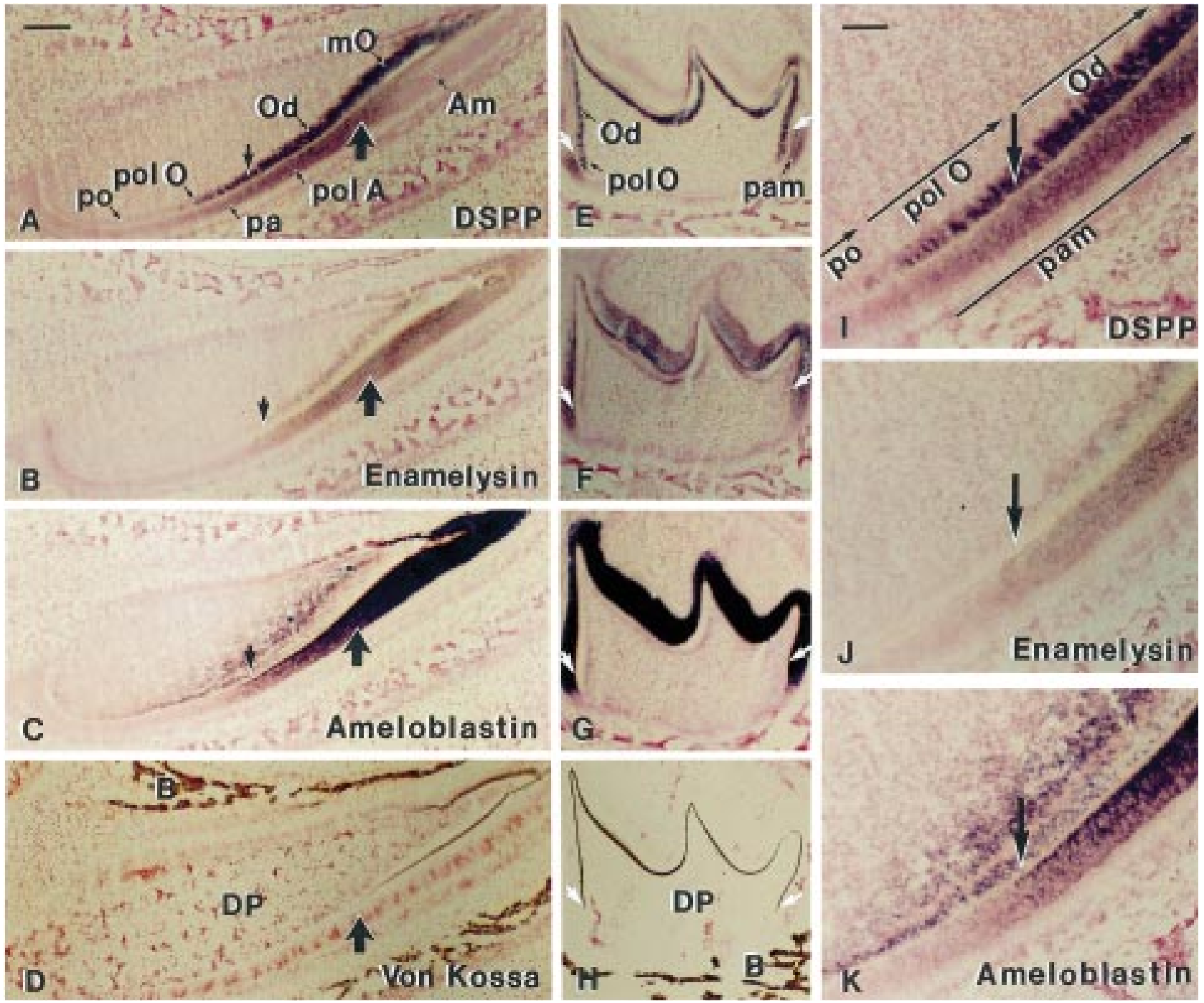

$\mathrm{K}$

Ameloblastin

Fig. 1. Gene expression of DSPP (A, E and I), enamelysin (B, F and J) and ameloblastin (C, G and K) correlated with the appearance of mineral ( $\mathrm{D}$ and $\mathrm{H}$ ) on consecutive sections of mouse mandibular newborn incisor (A-D and I-K) and 3-d-old molar $(\mathrm{E}-\mathrm{H})$. All three probes showed expression restricted to the tooth organ. The deposition of predentin (A-C and I-K) by differentiated odontoblasts (Od) and the onset of mineralization formation (A-C) tested by the Von Kossa technique (D and H) are illustrated by arrows pointing down and up, respectively. The start of mineralization in molars was indicated in both epithelial loops by small white arrows (E-G). DSPP mRNA was detected in polarizing odontoblasts (pol O), differentiated Od depositing predentin and mature odontoblasts $(\mathrm{mO})$ facing mineralized dentin (A, E, I). In addition, DSPP transcripts were transiently expressed in presecretory ameloblasts (pam), including preameloblasts (pa) and polarizing ameloblasts (pol A), but were never detected in secretory ameloblasts (Am), preodontoblasts (po), dental pulp cells (DP) or alveolar bone (B). Hybridization for enamelysin was detected at the onset of predentin secretion in Od and pol $\mathrm{A}$, and after mineralization in $\mathrm{mO}$ and $\mathrm{Am}(\mathrm{B}, \mathrm{F}$ and $\mathrm{J}$ ). Ameloblastin mRNA expressed in po and pol $\mathrm{O}$ was detected after predentin deposition in undifferentiated DP cells (see asterisks in $\mathrm{C}$ ), pol $\mathrm{A}$ and $\mathrm{Am}(\mathrm{C}, \mathrm{G}$ and $\mathrm{K})$. Details of the epithelio-mesenchymal interface during odontoblast differentiation (I-K) clearly showed that the three transcripts could be detected in both cell lineages (odontoblasts and ameloblasts) and presented distinct expression profiles. Magnification $=\mathrm{A}$ to $\mathrm{H}: \times 17$. Bar, $600 \mu \mathrm{M}$; I to $\mathrm{K}: \times 42$. Bar, $240 \mu \mathrm{M}$.

pointing down, Figs. 1B, J) and before the appearance of mineralized dentin (see wide arrow pointing up, Figs. 1B, D).

Ameloblastin mRNAs were expressed in polarizing and functional ameloblasts (Fig. 1C). Interestingly, although ameloblastin mRNAs were absent from odontoblasts, they were detected in preodontoblasts and polarizing odontoblasts as well as in undifferentiated pulp cells in the anterior part of the incisor (see asterisks in Fig. 1C). The point at which ameloblastin expression was no longer detected in the odontoblast layer (Fig. 1C) corresponded to the position where the initial deposition of predentin took place (see arrow pointing down in Figs. 1C, K).

Ameloblastin and enamelysin transcripts followed identical expression profiles in the ameloblast layer (compare Figs. 1B, J with Figs. 1C, K) and 
reached their highest levels at mineralizing and mineralized sites. All three tooth-specific transcripts were coexpressed in polarizing ameloblasts (Figs. 1A-C and Figs. 1I-K) at the position where odontoblast terminal differentiation occurred. The patterns of expression of DSPP and enamelysin transcripts were the same in 3-d-old molars as in newborn incisors at corresponding stages of cell development (compare Figs. 1E, F with Figs. 1A, B). Ameloblastin mRNAs, detected in the pulp cells of developing incisor (Fig. 1C), were absent in dental papillae cells of molars at an equivalent state of differentiation (Fig. 1G). Using all three toothspecific antisense riboprobes, no reactivity could be demonstrated in any other tissue, including bone (Figs. 1A-C), and sense riboprobes hybridized to control sections did not elicit any signal (not shown).

In summary, although DSPP and ameloblastin mRNAs were expressed in both cell types (odontoblasts and ameloblasts) along the epitheliomesenchymal junction, DSPP transcripts were predominantly expressed by differentiated odontoblasts, whereas the highest signal for ameloblastin transcripts was detected in differentiated ameloblasts. The labeling intensity for enamelysin mRNA appeared to be similar in differentiated cells located on both sides of the epithelio-mesenchymal interface.

\section{DSP and ameloblastin expressions in vivo}

In order to verify that DSPP and ameloblastin transcripts were translated into proteins at the epithelio-mesenchymal junction, immunohistochemistry and in situ hybridization experiments were performed on consecutive sections of 4-d-old mice molars using antibodies and riboprobes specific for both molecules (Fig. 2). The data in Fig. 2 show that cells displaying signals for DSPP and ameloblastin transcripts (Figs. 2B, C) expressed and secreted the corresponding translation products at the epithelio-mesenchymal junction (see arrows in Figs. 2A, D). Immunostaining of incisors using ameloblastin antibody revealed a weak signal in dental papillae cells that was barely distinguishable from the safranin-O counterstaining and requires further investigation (not shown). DSP was immunodetected in the cell bodies of differentiated odontoblasts, in their cell processes that were present in the tubular dentine (see small arrows in Fig. 2A) and extracellularly (see arrows pointing at the dentin-ameloblast interface in Fig. 2A). During molar development, DSPP (mRNA) and DSP (protein) that were expressed in presecretory ameloblasts were very briefly codetected with ameloblastin (mRNA and protein) at the onset of its synthesis, but were absent in secretory ameloblasts (see open arrows in Figs. 2A-D). Ameloblastin mRNA and protein were intensively detected in the distal cytoplasm of ameloblasts (Fig. 2C and 2D, respectively). Ameloblastin was deposited extracellularly at the secretory pole of differentiated ameloblasts (see arrows pointing at the dentin-ameloblast interface in Fig. 2D). Neither DSP nor ameloblastin could be detected in peridental tissues (including alveolar bone) or in control sections.

\section{Discussion}

DSP, DPP, enamelysin and ameloblastin are four ECM macromolecules exclusively expressed within the tooth $(14,22,35,43)$. Our present data showed that these molecules were expressed in early stages of dental cytodifferentiation, as well as by later, fully differentiated cells that were actively engaged in secreting ECM components. Interestingly, ameloblastin and DSPP, originally considered to be markers of differentiation for ameloblasts and odontoblasts, respectively $(14,17,31)$, showed transient mRNA expression during the early differentiation events in the opposite cell layers. Thus, preodontoblasts (already committed to an odontoblast pathway) expressed ameloblastin transcripts and presecretory ameloblasts synthesized DSPP transcripts. In each case, these transient mRNA expressions faded coincident with differentiation of the cells and subsequent deposition of ECM molecules.

Transient expression in preodontoblasts of markers currently known as "epithelial" has also been reported for the ameloblastin variant, amelin (34) and, at the protein level, for amelogenin. The amelogenin example however differs from this pattern, since its presence in the odontoblast layer might result from translocation processes involving endocytosis by the preodontoblasts after secretion of amelogenins by the facing inner dental epithelium (48). Except for DSP and DPP, there is little information concerning the expression of "mesenchymal" markers by the enamel organ. However, a recent study showed that BSP, secreted during early formation of dentin by odontoblasts (12) was also expressed by mature ameloblasts actively synthesizing the enamel matrix, as well as by epithelial cells present in ameloblastomas (49). In the present study, we have shown ameloblastin transcripts along the epithelio-mesenchymal interface, extending from predifferentiation to late maturation stages $(34,35)$.

Immunohistochemistry and in situ hybridization experiments on adjacent tissue sections showed that DSP and ameloblastin are deposited at the secretory 

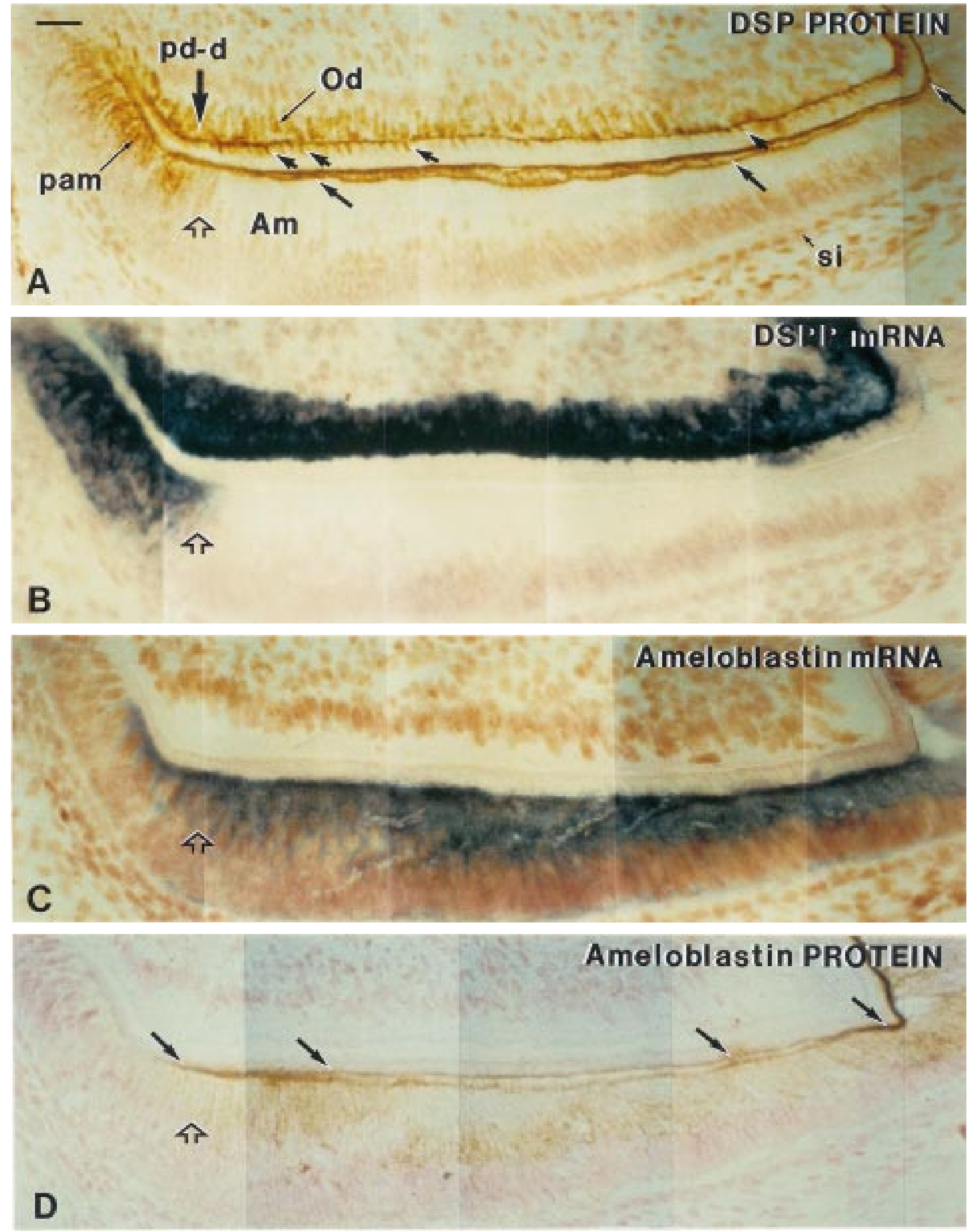

Fig. 2. Expression of DSP protein (A), DSP mRNA (B), ameloblastin mRNA (C) and ameloblastin protein (D) on serial sections of upper molar at four days of post-natal development. Immunohistochemistry revealed extracellular expression (see arrows at the epithelio-mesenchymal junction) for both DSP (A) and ameloblastin (D) at the proximity of the cells expressing the corresponding transcripts (B and C, respectively). Presecretory ameloblasts (pam) intensively expressed DSP protein and DSPP mRNA (A and B) until the onset of mineralization when predentin is converted into dentin (pd-d). This transition is indicated by an open arrow on each panel (A-D) and corresponds to the initiation of ameloblastin expression in ameloblasts (Am) at both mRNA and protein levels $(C$ and $D)$. si $=$ stratum intermedium. Magnification $=\times 168$. Bar, $60 \mu \mathrm{M}$. 
pole of the cells expressing the corresponding transcripts.

Here, transient expressions of tooth-specific molecules along the epithelio-mesenchymal interface indicates that these ECM proteins may be involved in cooperation with signaling molecules in processes leading to cytodifferentiation and biomineralization. Even though the exact role of ECM proteins is unknown, numerous studies have implied that epithelium- and mesenchyme-derived tooth-specific matrix proteins, along with other ECM macromolecules and soluble factors, take part in the cytodifferentiation processes leading to the mineralization of enamel and dentin (for review see Ruch et al. (1) and GoldBerG et al. (50)). ECM macromolecules mediating mineralization have been divided into two categories: 1) hydrophobic molecules that define the architecture of the system and the orientation of the crystal growth; and 2) the anionic molecules that play an active role in initiating, promoting and regulating crystal formation (such as DPP and possibly ameloblastin) and usually present at the interface of the structural components and the nucleating apatite crystals (19, $21,35)$.

Many ECM proteins are synthesized as larger, inactive precursors which are post-translationally modified (e.g., by glycosylation, phosphorylation, $\gamma$-carboxylation, or sulfation) and cleaved by proteinases on their way to the plasma membrane or in the extracellular space. These processes result in transformation of a precursor form to a macromolecule eliciting the appropriate function. The coding sequences for DSP and DPP are coexpressed as a single mRNA (DSPP) with the 5' end containing coding sequences for DSP and the $3^{\prime}$ end for DPP $(24,28)$. Yet, they are found as distinct proteins in dentin ECM. Thus, the initial translation product must be proteolytically processed in a manner that has not been elucidated. A toothspecific proteinase, enamelysin, that is expressed in differentiated dental cells (odontoblasts and ameloblasts) has recently been identified $(43,45)$. Based on high levels of expression of this enzyme in enamel organs and upon in vitro studies, BARTLETT et al. (45) have proposed that the amelogenins are substrates for enamelysin. The present work shows for the first time that enamelysin transcripts are also expressed prior to the onset of mineralization in sites where DSPP and ameloblastin translation products could be immunodetected. Based on this observation, we hypothesize that the active form of enamelysin may be involved in cleaving protein substrates (possibly including DSPP and ameloblastin) derived from odontoblasts or young ameloblasts, converting them from inactive precursors into their biologically active forms.
The present analysis of the distribution of toothspecific molecules provides an essential tool to delineate the biological functions of these molecules. The molecules studied display distinctive expression patterns along the epitheliomesenchymal interface, which support the possibility of interactions and related developmental functions during dental differentiations and the subsequent mineralization processes.

Acknowledgements - We express special thanks to Jeffrey Safran for valuable suggestions with regard to obtaining specific immunolabelings with both DSP and ameloblastin antibodies and for contributions during the preparation of this manuscript. We thank Dr. Rena N. D'Souza for helpful discussions. We also thank Jan Brunn for preparing the anti-DSP antibody. This work was supported by NIH grants R37 DE05092 (WTB) and DE12098 (JDB).

\section{References}

1. Ruch JV, Lesot H, BèGUe-Kirn C. Odontoblast differentiation. Int J Dev Biol 1995; 39: 51-68.

2. Thesleff I, VaAhtokari A, Kettunen P, Åberg $T$. Epithelial-mesenchymal signaling during tooth development. Connect Tissue Res 1995; 32: 9-15.

3. КосH WE. In vitro differentiation of tooth rudiments of embryonic mice: I. Transfilter interaction of embryonic incisor tissue. J Exp Zool 1967; 165: 155-170.

4. Slavkin HC, Bringas P. Epithelial-mesenchymal interactions during odontogenesis. IV. Morphological evidence for direct heterotypic cell-cell contacts. Dev Biol 1976; 50: $428-442$.

5. Karcher-Djuricic V, Staubli A, Meyer JM, Ruch J-V. Acellular dental matrices promote functional differentiation of ameloblasts. Differentiation 1985; 29: 169-175.

6. Warshawsky H, Smith, CE. Morphological classification of rat incisor ameloblasts. Anat Rec 1974; 179: 423-446.

7. Lesot H, Osman M, Ruch JV. Immunofluorescent localization of collagens, fibronectins, and laminin during terminal differentiation of odontoblasts. Dev Biol 1981; 82: 371-381.

8. Steinfort J, van de Stadt R, Beertsen W. Identification of new rat dentin proteoglycans utilizing $\mathrm{C} 18$ chromatography. J Biol Chem 1994; 269: 22397-22404.

9. Reichert T, Störkel S, Becker K, Fisher LW. The role of osteonectin in human tooth development: an immunohistochemical study. Calcif Tissue Int 1992; 50: 468-472.

10. BUTLER WT. The nature and significance of osteopontin. Connect Tissue Res 1989; 23: 123-136.

11. Bronckers AlJJ, Gay S, Finkelman RD, Butler WT. Immunolocalization of Gla proteins (osteocalcin) in rat tooth germs: comparison between indirect immunofluorescence peroxidase-antiperoxidase, avidin-biotin-peroxidase complex and avidin-biotin-gold complex with silver enhancement. J Histochem Cytochem 1987; 35: 825-830.

12. Chen J, McCulloch CAG, Sodek J. Bone sialoprotein in developing porcine dental tissues: cellular expression and comparison of tissue localization with osteopontin and osteonectin. Arch Oral Biol 1993; 38: 241-249.

13. George A, Sabsey B, Simonian PAL, Veis A. Characterization of a novel dentin matrix acidic phosphoprotein. Implications for induction of mineralization. $J$ Biol Chem 1993; 268: 12624-12630.

14. BUtLER WT, Ritchie H. The nature and functional significance of dentin extracellular matrix proteins. Int $J$ Dev Biol 1995; 39: 169-179. 
15. BUTLER WT. Dentin specific proteins. Methods Enzymol 1987; 145: 290-303.

16. Linde A, Goldberg M. Dentinogenesis. Crit Rev Oral Biol Med 1993; 4: 679-728.

17. Butler WT, Bhown M, Brunn JC, D'Souza RN, FarachCarson MC, Happonen R-P, Schrohenloher RE, Seyer JM, Somerman MJ, Foster RA, Tomana M, van Dijk S. Isolation, characterization and immunolocalization of a 53-kDal dentin sialoprotein. Matrix 1992; 12: 343-351.

18. Ritchie HH, Hou H, Veis A, Butler WT. Cloning and sequence determination of rat dentin sialoprotein, a novel dentin protein. $J$ Biol Chem 1994; 269: 3698-3702.

19. Rabie AM, VeIs A. An immunohistochemical study of the routes of secretion of collagen and phosphophoryn from odontoblasts into dentin. Connect Tissue Res 1995; 31: 197-209.

20. ButLer WT. Dentin matrix proteins and dentinogenesis. Connect Tissue Res 1995; 33: 59-65.

21. George A, Bannon L, Sabsay B, Dillon J W, Malone J, Veis A, Jenkins N A, Gilbert J, Copeland NG. The carboxy-terminal domain of phosphophoryn contains unique extended triplet amino acid repeat sequences forming ordered carboxyl-phosphate interaction ridges that may be essential in the biomineralization process. $J$ Biol Chem 1996; 271: 32869-32873.

22. Butler WT. Dentin matrix proteins Eur J Oral Sci 1998; 106: 204-210.

23. Bronckers AlJJ, D'Souza RN, Butler WT, LyaruU DM, van DiJK S, GAY S, Wöltgens JHM. Dentin sialoprotein: biosynthesis and developmental appearance in rat tooth germs in comparison with amelogenins, osteocalcin and collagen type-I. Cell Tissue Res 1993; 272: 237-247.

24. Bègue-Kirn C, Ruch JV, Ridall AL, Butler WT. Comparative analysis of mouse DSP and DPP expression in odontoblasts, preameloblasts, and experimentally induced odontoblast-like cells. Eur J Oral Sci 1998; 106: 254-259.

25. Ritchie HH, Berry JE, Somerman MJ, Hanks CT, Bronckers AlJJ, Hotton D, Papagerakis P, Berdal A, BUTLER WT. Dentin sialoprotein (DSP) transcripts: developmentally sustained expression in odontoblasts and transient expression in ameloblasts. Eur J Oral Sci 1997, 105 : $405-413$.

26. D'Souza Rn, Cavender A, Sunavala G, Alvarez J, Oshima T, Kulkarni B, MacDougall M. Gene expression patterns of murine dentin matrix protein 1 (DMP1) and dentin sialophosphoprotein (DSPP) suggest distinct developmental functions in vivo. J Bone Miner Res 1997; 12: 2040-2049.

27. Ritchie HH, WANG L-H. Sequence determination of an extremely acidic rat dentin phosphoprotein. $J$ Biol Chem 1996; 271: 21695-21698.

28. MacDougall M, Simmons D, Luan X, Nydegger J, Feng J, Gu TT. Dentin phosphoprotein and dentin sialoprotein are cleavage products expressed from a single transcript coded by a gene on human chromosome 4. J Biol Chem 1997; 272: 835-842.

29. Ogata Y, Shimokawa H, Sasaki S. Purification, characterization, and biosynthesis of bovine enamelins. Calcif Tissue Int 1988, 43: 389-399.

30. Fincham AG, Simmer JP. Amelogenin proteins of developing dental enamel. In: Chadwick DJ, Cardew G, eds. Dental enamel. Chichester, UK: John Wiley \& Sons Ltd., 1997; 118-134.

31. Krebsbach PH, Lee SK, Matsuki Y, Kozac CA, Yamada KM, YAMADA Y. Full-length sequence, localization, and chromosomal mapping of ameloblastin. J Biol Chem 1996; 271: 4431-4435.
32. Hu C-C, Fukae M, Uchida T, Qian Q, Zhang CH, Ryu OH, Tanabe T, Yamakoshi Y, Murakami C, Dohi N, SHimizu M, Simmer JP. Cloning and characterization of porcine enamelin mRNAs. J Dent Res 1997; 76: 1720-1729.

33. Cerný R, Slaby I, Hammarström L, Wurtz T. A novel gene expressed in rat ameloblasts codes for proteins with cell binding domains. J Bone Miner Res 1996; 11: 883-891.

34. Fong CD, Cerný R, Hammarström L, Slaby I. Sequential expression of an amelin gene in mesenchymal and epithelial cells during odontogenesis in rats. Eur J Oral Sci 1998; 106: 324-330.

35. Lee SK, Krebsbach PH, Matsuki Y, Nanci A, Yamada KM, YAMADA Y. Ameloblastin expression in rat incisors and human tooth germs. Int J Dev Biol 1996; 40: 1141-1150.

36. KaWAI T, URIST MR. Bovine tooth-derived bone morphogenetic protein. J Dent Res 1989; 68: 1069-1074.

37. Finkelman RD, Mohan S, Jennings JC, Taylor AK, JEPSEN S, BAYLINK DJ. Quantitation of growth factors IGF-I, SGF/IGF-II, and TGF- $\beta$ in human dentin. $J$ Bone Miner Res 1990; 5: 717-723.

38. Tagaki Y, Shinokawa H, Suzuki M, Nagai H, Sasaki S. Immunohistochemical localization of $\alpha_{2} \mathrm{HS}$ glycoprotein in dentin. Calcif Tissue Int 1990; 47: 40-45.

39. Goldberg M, Septier D, Lécolle S, Vermelin L, BissilaMapahou P, Carreau JP, Gritli A, Bloch-Zupan A. Lipids in predentine and dentine. Connect Tissue Res 1995; 33: $105-114$.

40. Fukae M, Tanabe T, Yamada M. Action of metalloproteinases on porcine dentin mineralization. Calcif Tissue Int 1994; 55: 426-435.

41. Fukae M, Tanabe T, Shimuzu M. Proteolytic enzyme activity in porcine immature enamel. Shigaku-Tsurumi Univ Dent $J$ 1977; 3: 15-17.

42. Overall CM, Limeback H. Identification and characterization of enamel proteinases isolated form developing enamel. Biochem J 1988; 256: 965-972.

43. Bartlett J D, Simmer JP, Xue J, Margolis HC, Moreno EC. Molecular cloning and mRNA distribution of a novel matrix metalloproteinase isolated from the porcine enamel organ. Gene 1996; 183: 123-128.

44. Simmer JP, Fukae M, Tanabe T, Yamakoshi Y, Uchida T, Xue J, Margolis HC, Shimizu M, Hu CC, Bartlett JD. Purification, characterization and cloning of enamel matrix serine proteinase 1. J Dent Res 1998; 77: 377-386.

45. Bartlett JD, Ryu OH, Xue J, Simmer JP, Margolis HC Enamelysin mRNA displays a developmentally defined pattern of expression and encodes a protein which degrades amelogenin. Connect Tissue Res 1998; in press.

46. ShEEHAN DC, HrapchaK BB. Theory and practice of histotechnology, 2nd edition. Columbus, OH: Batelle Press, 1980.

47. Bègue-Kirn C, Smith AJ, Loriot M, Kupferle C, Ruch JV, Lesot H. Comparative analysis of TGF $\beta$ s, BMPs, IGF1, msxs, fibronectin, osteonectin and bone sialoprotein gene expression during normal and in vitro-induced odontoblast differentiation. Int J Dev Biol 1994; 38: 405-420.

48. Nakamura M, Bringas Jr. P, Nanci A, Zeichner-David M, Ashdown B, Slavkin HC. Translocation of enamel proteins from the inner dental epithelia to odontoblasts during mouse tooth development. Anat Rec 1994; 238: 383-396.

49. Chen J, Sasaguri K, Aufdemorte TB, Jiang H, Thomas HF. Enamel epithelium expresses bone sialoprotein (BSP). Eur J Oral Sci 1998; 106: 331-336.

50. Goldberg M, Septier D, Lécolle S, Chardin H, Quintana MA, Acevedo AC, Gafni G, Dillouya D, Vermelin L, Thonemann B, Schmalz G, BissilaMapahou P, Carreau JP. Dental mineralization. Int J Dev Biol 1995; 39: 93-110. 